\title{
\& (5) \\ Effect of Different Surface-charged Lamellar Materials on Swelling Properties of Nanocomposite Hydrogels
}

Marcela Pfeifer

Universidade Federal de São Carlos

Flávio A. C. Andrade

Universidade Federal de São Carlos

Ricardo Bortoletto-Santos

Universidade Estadual Paulista: Universidade Estadual Paulista Julio de Mesquita Filho

Fauze A. Aouada

Universidade Estadual Paulista: Universidade Estadual Paulista Julio de Mesquita Filho

Caue Ribeiro ( $\nabla$ caue.ribeiro@embrapa.br)

Embrapa Instrumentation https://orcid.org/0000-0002-8908-6343

\section{Research Article}

Keywords: Montmorillonite, Hydrotalcite, Hydrogel, Methylcellulose, Nanocomposites, Swelling degree

Posted Date: February 25th, 2021

DOl: https://doi.org/10.21203/rs.3.rs-255558/v1

License: (c) (i) This work is licensed under a Creative Commons Attribution 4.0 International License. Read Full License

Version of Record: A version of this preprint was published at Journal of Polymers and the Environment on March 20th, 2021. See the published version at https://doi.org/10.1007/s10924-021-02120-7. 


\section{Abstract}

This study investigated the effect of different surface-charged lamellar materials on the swelling and diffusion properties of synthesized polyacrylamide-methylcellulose hydrogels ( $\mathrm{HG}$ ). Montmorillonite and hydrotalcite thermally activated at two different temperatures $\left(300\right.$ and $550{ }^{\circ} \mathrm{C}$ ) were incorporated in the preparation of nanocomposite (NC) hydrogels. A series of NC hydrogels were prepared by varying the lamellar material content $(1: 1,2: 1$ and $4: 1)$. The results showed that the $\mathrm{HG}$ with hydrotalcite $\left(550{ }^{\circ} \mathrm{C}\right)$ was strongly dependent on the ionic intensity, and that the swelling degree increased by $50 \%, 65 \%$ and $78 \%$ with reducing the hydrotalcite content at (1:1), (2:1) and (4:1), respectively. The water absorption capacity of $\mathrm{HG}$ containing montmorillonite or hydrotalcite $\left(300^{\circ} \mathrm{C}\right)$ was slightly affected when the $\mathrm{pH}$ decreased from 7 to 3 . However, the $\mathrm{pH}$ variation from 7 to 10 increased the water absorption capacity of most $\mathrm{HG}$, except those containing hydrotalcite $\left(550^{\circ} \mathrm{C}\right)$ at $(2: 1)$ and $(4: 1)$. The presence of lamellar nanoparticles in hydrogels made the polymer matrix more rigid, and less likely to absorb water. In contrast, $\mathrm{HG}$ with hydrotalcite $\left(550^{\circ} \mathrm{C}\right)$ at $(2: 1)$ and $(4: 1)$ showed anomalous behavior with an increase in their water absorption capacity. The results support that the developed NC-HG can be suitable candidates for applications as controlled released materials.

\section{Introduction}

Superabsorbent materials, such as hydrogels, have attracted considerable attention due to their elevated water retention capacity as well as their vast potential for application in drug release, wastewater treatment and agriculture [1-4]. The intercalation of different hydrophilic monomers - such as in polyacrylamide/methylcellulose (PAAm-MC) or carboxymethylcellulose blends - is a promising approach to increase the swelling capacity of hydrogels, while replacing part of base polymer with renewable sources. Methylcellulose is an abundant, renewable, and biodegradable polysaccharide that has been added to acrylamide solutions to synthesize hydrogels with high hydrophilicity, due to the hydroxyl groups present in its structure. Polyacrylamide hydrogels are not biologically degraded and when replacing part of acrylamide with methylcellulose, there is a double gain: 1) insertion of glycosidic groups, which facilitates the hydrogel decomposition by bacteria and fungi; and 2) reduction of possible residues formed after the composite degradation process, contributing to minimize the toxicity potential of PAAmMC systems for environmental applications [5-9].

Interpenetrating polymer network (IPNs) structures are generally used to control the hydrophilicity and release kinetics of hydrogels, since they are preferable in several biomedical and biotechnological applications due to their unique properties [10]. Semi-IPN polymers are prepared by dissolving a linear polymer in a hydrophilic monomer and a crosslinking agent. Thus, a synthetic hydrogel network is formed around a primary polymer chain that modifies the behavior of the hydrogel [11-12]. Moreover, the preparation of nanocomposite (NC) hydrogels compounding with lamellar materials results in systems with optimized mechanical, sorption, and nutrient desorption properties. It is possible to obtain responsive hydrogels, especially to environmental (or external) stimuli, such as temperature, $\mathrm{pH}$, ionic strength and pressure [13-14]. As an example, Junior et al. (2020) prepared pH-responsive 
poly(methacrylic acid)/laponite RDS hydrogels, and the influence of laponite on pKa, as well as the dependence between water absorption capacity and clay mineral content were evidenced [14].

Hydrogel nanocomposites have been developed for the controlled release of ionic compounds, such as fertilizers, mainly because the filler modifies the diffusion properties of the polymeric matrix [15-17]. Thus, NC hydrogels can be mixed with fertilizer sources, most of them ionizable compounds that provide the nutrients by dissolution (phosphates, nitrates, sulfates, etc.). However, these modifications often reduce the hydrogel swelling capacity due to the competition of modifiers with adsorption sites in the polymer network. For instance, Bortolin et al. (2016) analyzed the swelling performance of borate-loaded hydrogels, showing a remarkable reduction (more than 2 orders of magnitude) in their swelling due to interaction with the ionic solution [18-19]. Moreover, the development of NC hydrogels, incorporating lamellar nanomaterials in the chemically reticulated hydrogel network, allows the lamellae to act as a multifunctional cross linker in the formation of polymer-clay networks. Lamellar materials are highly hydrophilic and display high cationic (or anionic) exchange capacity and, therefore, they have affinity towards the hydrogel hydrophilic chains. In this context, the incorporation of layered double hydroxides (LDH) and smectites, such as hydrotalcite (HT) and montmorillonite (MMt), respectively, allow improvements not only in mechanical properties, but also in sorption and desorption of nutrients. HT and MMt stand out as candidate modifiers, given their characteristics and behavior of interaction with cations and/or anions into the polymeric network [20-25].

Herein, we investigated the role played by the surface charge of lamellar filler on the swelling and diffusion properties of montmorillonite- or hydrotalcite-loaded polyacrylamide/methylcellulose (PAAm$\mathrm{MC}$ ) hydrogels. The effect of the lamellar materials on the swelling degree was correlated with the structural and morphological properties of nanocomposite hydrogels. In this way, NC hydrogels were characterized, and their degree of swelling was evaluated in water and solutions with variable $\mathrm{pH}$ or salt concentration $(\mathrm{NaCl})$.

\section{Materials And Methods}

2.1. Synthesis of hydrogels. The polyacrylamide-methylcellulose/hydrotalcite (PAAm-MC/HT) and polyacrylamide-methylcellulose/montmorillonite (PAAm-MC/MMt) hydrogels were obtained by in situ polymerization of acrylamide monomer (AAm, $3.73 \mathrm{w} / \mathrm{v} \%, 98.53 \%$ purity, Neon), methylcellulose (MC, 0.25 $\mathrm{W} / \mathrm{v} \%$, molar mass $40.000 \mathrm{~g} \mathrm{~mol}^{-1}$, viscosity $400 \mathrm{cP}$, Sigma-Aldrich) and N'-N-methylene bisacrylamide (MBAAm, $5.40 \mu \mathrm{mol} \mathrm{mL} \mathrm{mL}^{-1}, 99 \%$ purity, Sigma-Aldrich). The reagents were placed in a bottle and homogenized by stirring. Different amounts of lamellar nanoparticles (calcium montmorillonite or commercial hydrotalcite, MMt and HT, respectively) were added to the solution, as shown in Table 1. 
Table 1

Acrylamide monomer (AAm), methylcellulose (MC), montmorillonite (MMt) and hydrotalcite $(\mathrm{HT})$ concentrations used in the synthesis of hydrogels. The concentrations of MBAAm, TEMED and $\mathrm{Na}_{2} \mathrm{~S}_{2} \mathrm{O}_{8}$ were kept constant at $5.40 \mu \mathrm{mol}$ $\mathrm{mL}^{-1}, 3.33 \mu \mathrm{mol} \mathrm{mL} \mathrm{L}^{-1}$ and $0.05 \mathrm{~g}$, respectively.

\begin{tabular}{|lllllll|}
\hline Materials & \multicolumn{2}{l}{ (w/v\%) } & & & & (w/w\%) \\
\cline { 2 - 7 } & AAm & MC & HT550 & HT300 & MMt & Lamellar material \\
\hline HG & 3.73 & 0.25 & 0 & 0 & 0 & 0 \\
\hline HG550 (1:1) & 3.73 & 0.25 & 4.0 & 0 & 0 & 50.0 \\
\hline HG550 (2:1) & 3.73 & 0.25 & 2.0 & 0 & 0 & 33.0 \\
\hline HG550 (4:1) & 3.73 & 0.25 & 1.0 & 0 & 0 & 20.0 \\
\hline HG300 (1:1) & 3.73 & 0.25 & 0 & 4.0 & 0 & 50.0 \\
\hline HG300 (2:1) & 3.73 & 0.25 & 0 & 2.0 & 0 & 33.0 \\
\hline HG300 (4:1) & 3.73 & 0.25 & 0 & 1.0 & 0 & 20.0 \\
\hline HGMMt (1:1) & 3.73 & 0.25 & 0 & 0 & 4.0 & 50.0 \\
\hline HGMMt (2:1) & 3.73 & 0.25 & 0 & 0 & 2.0 & 33.0 \\
\hline HGMMt (4:1) & 3.73 & 0.25 & 0 & 0 & 1.0 & 20.0 \\
\hline
\end{tabular}

Hydrotalcite was previously heat-treated using a muffle $\left(30^{\circ} \mathrm{C} \mathrm{min}-1\right)$ at $300^{\circ} \mathrm{C}$ and $550{ }^{\circ} \mathrm{C}$ for 120 min. These calcination temperatures were chosen based on previous reports [26-27], which indicate that at $300{ }^{\circ} \mathrm{C}$ the hydration water is lost, but the $\mathrm{HT}$ structure remains unchanged. Yet at $550^{\circ} \mathrm{C}$, the structural water, as well as the hydrotalcite structure is lost. The use of both temperatures allowed two conditions of water interaction in the hydrotalcite structure to be compared. In addition, the miscibility of HT in water was observed after heating at temperatures above $300^{\circ} \mathrm{C}$, which is why the hydrotalcite calcined at $300^{\circ} \mathrm{C}$ (HT300) was chosen to compose one of the synthesized hydrogels. For the other synthesis, the HT calcined at $550^{\circ} \mathrm{C}$ (HT550) was used, expecting to obtain a sample with new properties, since HT was totally unstructured, when compared to the HG synthesized with HT300. The prepared mixtures were deoxygenated by $\mathrm{N}_{2}$ bubbling for $20 \mathrm{~min}$. Then, the catalyst $\mathrm{N}, \mathrm{N}, \mathrm{N}^{\prime}, \mathrm{N}^{\prime}$-tetramethyl-ethylenediamine (TEMED, $3.33 \mu \mathrm{mol} \mathrm{mL} \mathrm{mL}^{-1}, 99 \%$ purity, Sigma-Aldrich) and sodium persulfate $\left(\mathrm{Na}_{2} \mathrm{~S}_{2} \mathrm{O}_{8}, 0.05 \mathrm{~g}, 99 \%\right.$ purity, Sigma-Aldrich) was added to initiate the polymerization reaction via free radical [28-29].

The resulting solution was quickly placed between two glass plates $(10 \times 10 \mathrm{~cm})$ separated by a rubber gasket $(0.5 \mathrm{~cm})$ and kept at room temperature for $24 \mathrm{~h}$. The hydrogels were purified by dialysis with distilled water for five days and the water was changed every $24 \mathrm{~h}$. The hydrogels were cut into a cylindrical shape $\left(2.4 \mathrm{~cm}\right.$ in diameter) and dried at $30^{\circ} \mathrm{C}$. Hydrogels were named (1:1), (2:1), (4:1), and (1:0), which represent the samples prepared with $50 \% \mathrm{w} / \mathrm{w}, 33 \% \mathrm{w} / \mathrm{w}, 20 \% \mathrm{w} / \mathrm{w}$, and $0 \% \mathrm{w} / \mathrm{w}$ (control) of 
lamellar material. The acronyms HGMMt, HG300, and HG550 were used for hydrogels synthesized with montmorillonite or hydrotalcite calcined at $300^{\circ} \mathrm{C}$ or $550^{\circ} \mathrm{C}$, respectively.

The hydrogels were characterized by X-ray diffraction (XRD), Fourier Transform Infrared (FTIR) spectroscopy, solid-state Nuclear Magnetic Resonance (NMR) spectroscopy and Scanning Electron Microscopy (SEM). Full description is included in the Supplementary Material.

2.2. Swelling degree. The hydrophilicity of NC hydrogels was studied by swelling degree (Q) measurements in aqueous solution. The swelling degree was evaluated at different times to obtain the swelling kinetics. The samples were dried, weighed, and subsequently immersed in Milli-Q $\circledast$ water under different conditions ( $\mathrm{pH}$ variation and ionic strength). The swelling degree was evaluated at three different $\mathrm{pH}$ values $(4.0,7.0$ and 10.0$)$ and three values of ionic intensity $\left(0.025,0.10\right.$ and $\left.0.20 \mathrm{~mol} \mathrm{~L}^{-1}\right)$. Each dried sample was submerged into $50 \mathrm{~mL}$ of each solution/medium. The $\mathrm{pH}$ and ionic intensity of the medium were adjusted using $\mathrm{HCl}(\mathrm{aq})$ or $\mathrm{NaOH}(\mathrm{aq})$ and $\mathrm{NaCl}(\mathrm{aq})$, respectively. The measurements were done in triplicate $(n=3)$ under controlled temperature $\left(T=25^{\circ} \mathrm{C}\right)$. The standard deviations were calculated and presented with the results. The swelling degree was calculated according to Eq. 1, in which $M_{t}$ and $M_{0}$ correspond to the swollen hydrogel mass at time $t$ and initial dried hydrogel mass, respectively [30-32].

$Q=M t / M_{0}($ Eq. 1)

The samples were monitored until no significant mass variation was observed $(\leq 0.05)$, indicating that the NC hydrogel reached a dynamic equilibrium. Moreover, the water absorption of samples was evaluated after 15 swelling cycles (re-swelling) to assess the loss of hydrophilic properties. Dried samples were immersed in $250 \mathrm{~mL}$ of Milli-Q® water at $25^{\circ} \mathrm{C}$ until equilibrium was reached. Then, the samples were removed from the medium and dried in an oven at $30^{\circ} \mathrm{C}$. This process was done in triplicate for each HG formulation.

2.3. Kinetic Parameters. The swelling kinetic parameters were determined to compare the diffusional water absorption process between the different hydrogels. The comparison was performed using the Ritger-Peppas model, as shown in Eq. 2 [33-34]. In Eq. 2, $t$ is the time, $k$ is the diffusion kinetic constant, $n$ is the diffusional exponent, and $M_{t}$ and $M_{e q}$ are the sample mass at time t of swelling and steady state, respectively.

$k t^{n}=M_{t} / M_{e q}($ Eq. 2)

The Ritger-Peppas model can be applied to fit the initial stages to approximately $60 \%$ of swelling degree, since the swelling behavior is an ascending straight line over time under these conditions. Above this point, the swelling degree tends to level off with no mass variation over time, thus the slope tends to zero [35-36]. Thus, to obtain the $n$ and $k$ values, graphs of $\ln M_{t} / M_{\infty} v s$. In $(t)$ were plotted for each treatment, and $n$ and $k$ were determined as the angular and linear coefficients, respectively. 


\section{Results And Discussion}

\subsection{Chemical and physical characterization}

Figure 1 shows the XRD patterns of hydrotalcite $(\mathrm{HT})$ calcined at different temperatures. The hydrotalcite structure remained stable until $200^{\circ} \mathrm{C}$, keeping the symmetrical reflections at $2 \theta=11.6^{\circ}$ and $23.3^{\circ}$ ascribed to (003) and (006) basal planes, respectively. The patterns also revealed the presence of asymmetric reflections at $2 \theta=60.7^{\circ}$ and $62.1^{\circ}$ of (110) and (113) non-basal planes, respectively, similarly to hydrotalcite at $25^{\circ} \mathrm{C}$. However, significant structural changes occurred above $300^{\circ} \mathrm{C}$, as the primary reflections were not observed. Specifically, the lamellar structure collapsed between $400^{\circ} \mathrm{C}$ and $550^{\circ} \mathrm{C}$, leading to the formation of a mixed $\mathrm{Mg} / \mathrm{Al}$ oxide - indicated by the reflections at $2 \theta=40-45^{\circ}$ and $2 \theta=$ $60-65^{\circ}$. Moreover, the (003) basal reflection shifted to a higher diffraction angle, suggesting that a fraction of particles was their lamellar structure collapsed and/or unstructured.

Figure 2 shows the XRD patterns of the lamellar materials and their respective nanocomposite hydrogels. MMt showed a well-defined diffraction peak at $2 \theta=6.6^{\circ}$, corresponding to the characteristic montmorillonite phase with an interlayer distance $d_{001}=1.35 \mathrm{~nm}$. On the other hand, the pattern revealed that the reflection at $6.6^{\circ}$ was not perceptible in the nanocomposite hydrogels (HGMMt), suggesting that MMt was exfoliated and/or intercalated into the hydrogel matrix. Similar results were observed by Bortolin et al., 2013 [3]. Moreover, it was possible to note reflections at $2 \theta=25$ and $27^{\circ}$, which corresponded to common contaminants found in mineral-derived materials as impurity phases, such as quartz and feldspar.

Figures $2 \mathrm{~b}$ and $2 \mathrm{c}$ show the XRD patterns of hydrogels containing hydrotalcite - HG550 and HG300. The HG550 sample matrixes showed a small displacement of the crystallographic plane (003) at $2 \theta=11.5^{\circ}$. Partial delamination of lamellar material is expected when the diffraction peak is broadened, suggesting formation of tactoids dispersed within the hydrogel matrix at a nanometric scale, although no significant shift was seen.

Figure 3 shows the FTIR spectra of pure $(\mathrm{HG})$ and different modified hydrogels at the 1:1 proportion. All hydrogels (modified or not) exhibited characteristic bands of polyacrylamide, referring to the $\mathrm{NH}_{2}$ stretching vibration modes $\left(3300-3450 \mathrm{~cm}^{-1}\right)$, and stretching vibrations of $\mathrm{C}=\mathrm{O}$ bond (1667 and 1466 $\left.\mathrm{cm}^{-1}\right)$ and $\mathrm{C}-0$ group $\left(1153 \mathrm{~cm}^{-1}\right)$. The stretching vibration bands between 2990 and $3600 \mathrm{~cm}^{-1}$ were attributed to hydroxyl groups. The characteristic bands of $\beta$-glycosidic bonds were observed at the $900-$ $1230 \mathrm{~cm}^{-1}$ region, referring to the monosaccharide units of methylcellulose.

The bands referring to MMt in the spectrum of HGMMt were observed at $1010-1110 \mathrm{~cm}^{-1}, 914-930$ $\mathrm{cm}^{-1}$ and $400-800 \mathrm{~cm}^{-1}$, corresponding to axial deformations of $\mathrm{Si}-\mathrm{O}, \mathrm{Al}-\mathrm{OH}-\mathrm{Al}$ angular vibrations, and angular deformations of $\mathrm{Si}-\mathrm{O}$ bonds, respectively. Also, the bands referring to $\mathrm{HT}$ in the $\mathrm{HG} 550$ and HG300 spectra were observed at $1360-1485 \mathrm{~cm}^{-1}$ and $850 \mathrm{~cm}^{-1}$, corresponding to the symmetrical stretching of interlamellar carbonate and carbonate deformation, respectively. Moreover, the hydration 
water and hydroxyl groups present in the HT structure were recorded close to $3440 \mathrm{~cm}^{-1}$, which presents a broad and intense band [37-38].

The results suggest that $\mathrm{HG} 550$ had more interlayer carbonates than $\mathrm{HG} 300$, given the higher number of bands attributed to symmetric stretching modes of carbonate $\left(1360-1485 \mathrm{~cm}^{-1}\right)$. A third band (only in HG550 - Fig. 3b) at $1556 \mathrm{~cm}^{-1}$ can be associated with the presence of carboxylates ( $\left.\mathrm{COO}^{-}\right)$in the hydrogel structure, since $\mathrm{HT}$ calcined at $550^{\circ} \mathrm{C}$ forms more $\mathrm{Mg} / \mathrm{Al}$ oxides than hydrotalcite calcined at $300^{\circ} \mathrm{C}[39]$. This phenomenon occurs during hydration, in which the oxides are converted to hydroxides, influencing the conversion of amide to carboxylic acid groups. Furthermore, no suppression or displacement of the hydrogel bands was observed, implying that the nanoclays-hydrogel interaction is weak.

The ${ }^{13} \mathrm{C}$ nuclear magnetic resonance (NMR) spectra of precursor materials (MC and AAm) used in the synthesis of hydrogels are shown in Figs. $4 a$ and $4 b$. The MC presented intense peaks at $\delta=61.30$ and $75.18 \mathrm{ppm}$, which refer to the $\mathrm{C} 6, \mathrm{C} 7, \mathrm{C} 8$ and $\mathrm{C} 2, \mathrm{C} 3, \mathrm{C} 5$ carbons, respectively. In addition, assignments of Am were observed at $\delta=128.09,130.45$ and $169.47 \mathrm{ppm}$, which refer to the $\mathrm{C} 2, \mathrm{C} 1$ and $\mathrm{C} 3$ carbons, respectively. Figure $4 \mathrm{c}$ shows the ${ }^{13} \mathrm{C}$ NMR spectra of the pure hydrogel, HG300 (1:1) and HG550 (1:1). The most intense peaks at $\delta=41.92$ and 180.50 ppm were found in all spectra and refer to C1, C2 and C3, C5 carbons from polyacrylamide structure, respectively. The small-signal at $\delta=59.63 \mathrm{ppm}$ refers to the polyacrylamide $\mathrm{C} 4$ carbon. A new peak around $\delta=170.70$ ppm was found in the spectra of HG550 (1:1) and HG300 (1:1). This result indicates that a new chemical environment was formed by reactions involving the $\mathrm{C} 3$ and/or C5 carbons, suggesting a change in the network structure of nanocomposite hydrogels. This behavior was intensified when the calcination temperature was increased. FTIR confirms that the hydrolysis process was more efficient in the lamellar material calcined at $550^{\circ} \mathrm{C}$ (Fig. 3). Moreover, no peaks referring to AAm carbons (residual AAm) were found, indicating the complete polymerization of AAm after hydrogel formation. This suggests that relevant toxicity is not expected, since polyacrylamide is relatively stable and does not form significant acrylamide amounts in its degradation cycle, being considered non-toxic [40].

The ${ }^{27} \mathrm{Al}$ NMR spectra (Fig. 5) indicated that the HT calcination at $550^{\circ} \mathrm{C}$ only changed the Al chemical environment, as indicated by the peak widening, and shift from $\delta=9.05$ to $13.11 \mathrm{ppm}$. However, the calcination process of $\mathrm{HT}$ at $300^{\circ} \mathrm{C}$ was insufficient to change its internal structure, given that the NMR spectrum of $\mathrm{HT}$ at this temperature was similar to that obtained at room temperature, e.g., no thermal treatment. Thus, this more pronounced change for HG550 indicates that hydrotalcite was unstructured at this temperature, intensely modifying the chemical environment of $\mathrm{Al}$, as already discussed in the XRD patterns (Fig. 2).

The ${ }^{27}$ Al NMR spectra of modified hydrogels (Fig. 5b) revealed that both systems regenerated the initial coordination of $\mathrm{HT}$. However, an inversion was observed for HG550, which formed a hydrogel with aluminum in a less diversified chemical environment than in HT. In addition, this environment was similar to the original HT structure, indicating that the HT lamellas were restructured to a higher extent into the 
hydrogel matrixes. On the other hand, a divergent profile compared to the original $\mathrm{HT}$ structure was obtained when using $\mathrm{HT}$ calcined at $300^{\circ} \mathrm{C}$ (HG300), suggesting a less effective lamellar regeneration.

Figure 6 shows SEM micrographs of the fractured surfaces of HG, HG550, HG300 and HGMMt synthesized at the 1:1 proportion. In general, it was observed that the samples presented a porous structure with an irregularly leaf-shaped distribution or foliaceous characteristic. This morphology is typical of polysaccharide-based hydrogels, as described by Bortolin et al., 2013 [3]. However, a qualitative analysis of the micrographs at larger magnifications revealed that HG550 had a larger pore size than the other samples. Moreover, small piles or tactoids were well spread on the external walls of HG550, forming an organic-inorganic hybrid structure, thus confirming a better dispersion of $\mathrm{HT}$ calcined at $550^{\circ} \mathrm{C}$. A series of agglomerated particles or tactoids on the HG300 polymeric network walls was also observed, indicating the formation of an organic-inorganic hybrid structure. On the other hand, HGMMt had no traces of lamellar structures stacked on the polymeric network walls, indicating that this lamellar material was exfoliated and/or interspersed throughout the hydrogel matrix.

\subsection{Swelling degree and kinetic parameters}

Figures 7 and 8 show the swelling degree values as a function of time and the swelling degree at equilibrium $\left(\mathrm{Q}_{\mathrm{eq}}\right)$ for all nanocomposite systems. The swelling reduced for HT300 and all the MMtcontaining samples. The addition of lamellar materials during the synthesis of hydrogels impacted the swelling capacity, probably because the nanostructures made the polymeric matrixes less flexible due to the hindered chain mobility. This was evidenced by the gradual reduction in the $\mathrm{Q}_{\mathrm{eq}}$ values with calcination temperature, e.g. $Q_{\text {eq }}$ for HGMMt was higher than HG300, which still had some bounded water in the HT structure. However, the HT calcinated at $550^{\circ} \mathrm{C}$ significantly affected the water uptake of HG550 with an anomalous increase of $Q_{\text {eq }}$ by $179 \%$ and $152 \%$ for the (4:1) and (2:1) treatments, respectively, when compared to HG. This behavior can be associated with the regeneration of hydrotalcite structure. In contrast, when compared to the same control matrix - HG, it was observed a reduction of $41 \%$ (similar to $\mathrm{HG} 300$ ) in the $\mathrm{Q}_{\mathrm{eq}}$ values of $\mathrm{HG} 550$ (1:1). The fully unstructured hydrotalcite $\left(550^{\circ} \mathrm{C}\right)$ attained a better dispersion in the polymeric matrix, as observed in the SEM images (Fig. 6). This dispersion generated an adequate arrangement of the lamellar active centers, allowing the insertion of molecules in the HT galleries and increasing the hydrogel swelling degree. Probably, these lamellar materials acted as labile bridges in the hydrogel structure, leading to a synergistic effect in the swelling degree. Other effects are related to the increase of osmotic pressure gradient formed by the difference between the external and internal media caused by the cations coming from nanoclay, and the increase of electrostatic repulsion between $\mathrm{O}^{-}$(hydrogel matrix) and $\mathrm{Si}^{-\mathrm{O}^{-}}$(nanoclay) anionic groups. Similar hydrophilic behavior was observed by Junior et al., 2020, for poly(methacrylic acid)/laponite RDS nanocomposite hydrogels.

The reduction observed in $Q_{e q}$ for the (1:1) hydrogels probably occurred due to the excess of lamellar material, which affects the polymer chain rigidity, as evidenced by FTIR and NMR characterizations. Thus, 
depending on the HT annealing, the lamellae regeneration during the hydrogel synthesis is favored, corroborating with the NMR results.

Table 2 shows the kinetic swelling parameters of the different hydrogels. The $n$ values were between 0.5 and 1.0 for HGMMt (1:1), HG550 (2:1) and (4:1) (Table 2), indicating that the diffusion process occurred by anomalous transport. The highest value was obtained for the hydrogel with higher mobility of polymer chains (4:1). These results agree with the swelling degree values found for this sample. However, it is possible to notice $n$ values close to 0.50 for HG (without lamellar material) and HG550 (1:1), which corresponds to Fickian diffusion, that is, water molecules are transported through the hydrogel structure by simple diffusion processes. Moreover, $n<0.50$ were observed for all the other samples, suggesting that the nanoparticles made the polymer chains more rigid. This result was expected due to the possibility of the lamellar materials to act as physical barriers, influencing the diffusion and chain mobility.

Table 2

Kinetic swelling parameters of different hydrogels synthesized using water as swelling medium.

\begin{tabular}{|lll|}
\hline Hydrogel & $\mathbf{n}$ & $\boldsymbol{k}\left(\mathbf{x ~ 1 0}^{-2}\right)\left(\mathbf{h}^{-1}\right)$ \\
\hline HG & $0.47 \pm 0.02$ & 45.87 \\
\hline HG550 (1:1) & $0.45 \pm 0.01$ & 51.98 \\
\hline HG550 (2:1) & $0.57 \pm 0.03$ & 47.15 \\
\hline HG550 (4:1) & $0.70 \pm 0.04$ & 37.14 \\
\hline HG300 (1:1) & $0.21 \pm 0.01$ & 66.47 \\
\hline HG300 (2:1) & $0.22 \pm 0.01$ & 68.58 \\
\hline HG300 (4:1) & $0.12 \pm 0.01$ & 80.34 \\
\hline HGMMt (1:1) & $0.69 \pm 0.01$ & 52.87 \\
\hline HGMMt (2:1) & $0.32 \pm 0.02$ & 65.26 \\
\hline HGMMt (4:1) & $0.31 \pm 0.01$ & 70.13 \\
\hline
\end{tabular}

The increase in the lamellar material content matrixes decreased the $k$ parameter for the HGMMt and HG300 series, suggesting a slower water absorption. However, an opposite effect was observed for the HG550 treatments, indicating that the water absorption occurred more quickly in these samples, with the highest absorption occurring for HG550 (1:1). Again, this is an evidence of the role played by the hydrotalcite regeneration process in the hydrogel structure, that is, the creation of more channels for water diffusion.

Figure 9 shows the swelling degree dependence at equilibrium $\left(\mathrm{Q}_{\mathrm{eq}}\right)$ of the different hydrogels synthesized under three different ionic strength values. It is possible to see that the $Q_{e q}$ values for all 
HGMMt and HG300 compositions were little affected with increasing the ionic strength (Figs. 9a and 9b). The presence of salts in the solution increases the osmotic pressure of the swelling medium, which is related to absorption of water. Moreover, it can be noted that there were no significant changes in the water absorption for these treatments (HGMMt and HG300) after reaching a dynamic balance/equilibrium.

In Fig. 9c, the $Q_{\text {eq }}$ values of the $\mathrm{HG} 550$ series substantially decreased by approximately $50 \%, 65 \%$ and $78 \%$ for the (1:1), (2:1) and (4:1) ratios, respectively, with increasing the ionic intensity, suggesting that these hydrogels (HG550) were salt-responsive. However, the samples with significant polymer mobility (observed by the swelling degree greater than that of $\mathrm{HG}$ ) had higher sensitivity to ionic strength. The decrease in $\mathrm{Q}_{e q}$ is, in part, due to the localized interactions between positive ions $\left(\mathrm{Na}^{+}\right)$and hydroxyl groups of $\mathrm{MC}$, inducing the formation of ${ }^{-} \mathrm{O}-\mathrm{Na}^{+}$ionic complexes. Consequently, this complex formation could decrease the electrostatic repulsions between $\mathrm{MC}$ chain segments, which are entanglement with the crosslinked PAAm chains, making the polymer network expansion difficult [41]. Another effect related to the decreased $Q_{e q}$ values is the stabilization of chloride anions by the anionic HT lamellas, which have positive charges on their surface, reducing the quantity of hydroxyl groups and water molecules inside the hydrogel as well as contributing to decrease the swelling degree.

It is worth mentioning that $\mathrm{HG}$ (composed exclusively of $\mathrm{Am}$ and $\mathrm{MC}$ ) was also salt-responsive, which is in line with the results reported by our research group [42]. The swelling degree of HG decreased by approximately $20 \%$ with the increase in ionic strength, although this reduction occurred to a lesser extent, when compared to the HG550 series. Probably, the main reason for this decrease is also related to the interactions between the $\mathrm{Na}^{+}$ions and hydroxyl groups of $\mathrm{MC}$, as previously explained. In this way, these results prove that the hydrotalcite played an essential role in the water uptake of the hydrogels in matrixes in saline medium.

The influence of $\mathrm{pH}$ on the swelling degree and $\mathrm{Q}_{\mathrm{eq}}$ values for the different synthesized hydrogels is shown in Fig. 10. It was observed that the water absorption capacity of HGMMt and HG300 was slightly affected when the pH decreased from 7.0 to 3.0 (Figs. 10a and 10b). This indicates that only a small fraction of amide groups in the polymer chains was ionized, which slightly contributed to the expansioncontraction of the hydrogel polymer chains. On the other hand, the $\mathrm{pH}$ variation from 7.0 to 10.0 increased the water absorption for most samples, suggesting that the synthesized hydrogels were $\mathrm{pH}$ responsive. These results agree with findings reported by other authors [43]. The control of the water uptake by $\mathrm{pH}$ and salt variation improves the applicability of the synthesized hydrogels, mainly in the agriculture field, such as for water remediation and controlled release of substances.

The HG550 (2:1) and (4:1) samples exhibited different behaviors (Fig. 10c), since their structures encompassed polymer chains with higher mobility, thus showing higher sensibility to changes in the external swelling solution, as discussed in the previous section. The decrease in $Q_{e q}$ observed at high or low $\mathrm{pH}$ values relates to the increase in the ionic intensity of medium, which occurred by increasing the 
number of sodium ( $\mathrm{pH}$ 10) or chloride $(\mathrm{pH} 3.0)$ ions, since $\mathrm{NaOH}$ or $\mathrm{HCl}$ solutions were used to adjust the $\mathrm{pH}$ of the swelling solution.

Figure 11 shows the $Q_{\text {eq }}$ values of each sample as a function of number of swelling cycles. When the hydrogel is subjected to the swelling process from its dry state to the maximum swelling, significant structural changes occur in the polymer chains. When the swelling/drying sequence is repeated consecutively, reorganization in the polymer chains can occur, causing small changes in the swelling degree between each cycle [44].

There was a tendency to decrease the hydrophilic property of HG with increasing the number of swelling cycles, while a slight variation was found for the hydrogels reinforced with lamellar materials (Figs. 11a and 11b). For the hydrogel with anomalous behavior (HG550 4:1), which have polymer chains with higher mobility, the variation in the swelling degree was more significant, but its hydrophilic property was not dependent on the swelling cycle number (Fig. 11c).

The tendency to maintain the swelling degree of nanocomposite hydrogels after several swelling/drying cycles can be explained by the dispersion of lamellar materials in hydrogel matrixes, protecting and reinforcing the polymeric network structure against damage during the drying process. These results indicate that the nanocomposites (HG550, HG300 and HGMMt) have improved behaviors with respect to the control $(\mathrm{HG})$, and that these materials can be reused favorably for up to fifteen cycles without losing their water retention effectiveness.

\section{Conclusion}

Nanocomposite hydrogels containing hydrotalcite or montmorillonite were successfully synthesized by in situ polymerization with different lamellar material proportions. The water absorption capacity of hydrogels containing montmorillonite and hydrotalcite (calcined at $300^{\circ} \mathrm{C}$ ) were slightly affected by $\mathrm{pH}$, since the presence of these lamellar nanoparticles increased the hydrogel polymer matrix rigidity. The hydrogels with hydrotalcite (calcined at $550^{\circ} \mathrm{C}-2: 1$ and 4:1) were strong dependent on the ionic strength of medium, and displayed anomalous behavior regarding the water absorption, increasing the swelling degree at equilibrium (Qeq) with decreasing the lamellar material content. Moreover, there were no significant changes in the water absorption properties of nanocomposite hydrogels when they were subjected to swelling/drying cycles.

\section{Declarations}

\section{ACKNOWLEDGMENTS}

The authors are thankful for the financial support given by FAPESP (São Paulo State Research Foundation, \#2013/03643-0; \#2013/07296-2, \#2016/10636-8, \#2019/18036-8 and \#2020/03259-9 grants), CAPES (Coordination for the Improvement of Higher Education Personne, CAPES-Embrapa Program), CNPq (Brazilian National Council for Scientific and Technological Development 
\#405680/2016-3 and \#312414/2018-8 grants), SISNANO/MCTI, FINEP, and Embrapa AgroNano research network. The authors also thank the National Nanotechnology Laboratory for Agribusiness (LNNA) for providing institutional support and facilities.

\section{DECLARATION ON CONFLICT OF INTEREST}

The authors declare that they have no conflict of interest.

\section{References}

[1] Pulat M, Tan N, Onurdağ FK (2011) Swelling dynamics of IPN hydrogels including acrylamide-acrylic acid-chitosan and evaluation of their potential for controlled release of piperacillin-tazobactam. J. Appl. Polym. Sci. 120:441-450

[2] Campese GM, Tambourgi EB, Guilherme MR, Moura MR, Muniz EC, Youssef EY (2007) Resistência mecânica de hidrogéis termo-sensíveis constituídos de Alginato-Ca2+/ PNIPAAm, tipo Semi-IPN. Quim Nova 30:1649-1652.

[3] Bortolin A, Aouada FA, Mattoso LHC, Ribeiro C (2013) Nanocomposite PAAm/methyl cellulose/montmorillonite hydrogel: evidence of synergistic effects for the slow release of fertilizers. J Agr Food Chem 61:7431-7439.

[4] Anirudhan TS, Mohan AM (2018) Novel pH sensitive dual drug loaded-gelatin methacrylate/methacrylic acid hydrogel for the controlled release of antibiotics. Int J Biol Macromol 110:167-178.

[5] Aouada FA, Moura MR, Orts WJ, Mattoso LHC (2011) Preparation and characterization of novel microand nanocomposite hydrogels containing cellulosic fibrils. J Agr Food Chem 59:9433-9442.

[6] Olad A, Zebhi H, Salari D, Mirmohseni A, Tabar AR (2018) Slow-release NPK fertilizer encapsulated by carboxymethyl cellulose-based nanocomposite with the function of water retention in soil. Mater Sci Eng c 90:333-340.

[7] Fernandes RS, Tanaka FN, Moura MR, Aouada FA (2019) Development of alginate/starch-based hydrogels crosslinked with different ions: hydrophilic, kinetic and spectroscopic properties. Mater Today Commun 21:100636.

[8] Meng Y, Liu XQ, Li CX, Liu H, Cheng Y, Lu J, Zhang K, Wang HS (2019) Super-swelling lignin-based biopolymer hydrogels for soil water retention from paper industry waste. Int J Biol Macromol 135:815820.

[9] Singh B, Kumar A (2020) Exploration of arabinogalactan of gum polysaccharide potential in hydrogel formation and controlled drug delivery applications. Int J Biol Macromol 147:482-492. 
[10] Pulat M, Uğurlu N (2016) Preparation and characterization of biodegradable gelatin-PAAm-based IPN hydrogels for controlled release of maleic acid to improve the solubility of phosphate fertilizers. Soft Materials 14:217-227.

[11] Pulat M, Özgündüz HI (2014) Swelling behavior and morphological properties of semi-IPN hydrogels based on ionic and non-ionic components. Biomed. Mater. Eng. 24(4):1725-1733.

[12] Pulat M, Akalın GO, Karahan ND (2014) Lipase release through semi-interpenetrating polymer network hydrogels based on chitosan, acrylamide, and citraconic acid. Artif. Cells Nanomed. Biotechnol. 42(2):121-127.

[13] Feng J, Dou J, Zhang Y, Wu Z, Yin D, Wu W (2020) Thermosensitive hydrogel for encapsulation and controlled release of biocontrol agents to prevent peanut aflatoxin contamination. Polymers 12:547.

[14] Junior CRF, Fernandes RS, Moura MR, Aouada FA (2020) On the preparation and physicochemical properties of $\mathrm{pH}$-responsive hydrogel nanocomposite based on poly(acid methacrylic)/laponite RDS. Mater Today Commun 23:100936.

[15] Tanaka FN,Ferreira CR, Moura MR, Aouada FA (2018) Water Absorption and Physicochemical Characterization of Novel Zeolite-PMAA-co-PAAm Nanocomposites. J Nanosci Nanotechnol 18:72867295.

[16] Nath J, Ahmed A, Saikia P, Chowdhury A, Dolui S (2020) Acrylic acid grafted gelatin/LDH based biocompatible hydrogel with pH-controllable release of vitamin B12. Appl Clay Sci 190:105569.

[17] Thakur B, Sharma G, Kumar A, Sharma S, Naushad M, Iqbal J, Stadler F (2020) Designing of bentonite based nanocomposite hydrogel for the adsorptive removal and controlled release of ampicillin. J Mol Liq 319:114166.

[18] Bortolin A, Serafim AR, Aouada FA, Mattoso LHC, Ribeiro C (2016) Macro- and micronutrient simultaneous slow release from highly swellable nanocomposite hydrogels. J. Agric. Food Chem. 64(16): 3133-3140.

[19] Akalin GO, Pulat M (2020) Preparation and characterization of k-carrageenan hydrogel for controlled release of copper and manganese micronutrients. Polymer Bulletin 77:1359-1375.

[20] Xia X, Yih J, Nandika AS, Hu Z (2003) Swelling and mechanical behavior of poly (Nisopropylacrylamide)/Na-montmorillonite layered silicates composite gels. Polymer 44:3389-3393.

[21] Peng L, Siddaramaiah NHK, Seok BH, Lee J (2008) Novel PAAm/Laponite clay nanocomposite hydrogels with improved cationic dye absorption behavior. Compos Part-B Eng 39:756-763.

[22] Yumei Y, Xiang S, Wang P (2009) Fabrication and characterization of microstructured and pH sensitive interpenetrating networks hydrogel films and application in drug delivery field. Eur Polym $\mathrm{J}$ 
[23] Bernardo MP, Guimarães GGF, Majaron VF, Ribeiro C (2018) Controlled release of phosphate from layered double hydroxide structures: dynamics in soil and application as smart fertilizer. ACS Sustain Chem Eng 6:5152-5161.

[24] Bortoletto-Santos R, Plotegher F, Majaron VF, da Silva MG, Polito WL, Ribeiro C (2020) Polyurethane nanocomposites can increase the release control in granulated fertilizers by controlling nutrient diffusion. Appl Clay Sci 199:105874.

[25] Okada A, Usuki A (2006) Twenty years of polymer-clay nanocomposites. Macromol Mater Eng 291:1449-76.

[26] Bernardo MP, Moreira FKV, Colnago LA, Ribeiro C (2016) Physico-chemical assessment of [Mg-AlP04]-LDHs obtained by structural reconstruction in high concentration of phosphate. Colloids Surf A: Physicochem Eng Asp 497:53-62.

[27] Bernardo MP, Moreira FKV, Ribeiro C (2017) Synthesis and characterization of eco-friendly Ca-Al-LDH loaded with phosphate for agricultural applications. Appl Clay Sci 137:143-150.

[28] Aouada FA, Guilherme MR, Campese GM, Girotto EM, Rubira AF, Muniz EC (2006) Electrochemical and mechanical properties of hydrogels based on conductive poly(3,4-ethylenexythiophene) / poly(styrenesulfonate) and PAAm. Polymer Testing 25:158-165.

[29] Bodugoz-Senturk H, Macias CE, Kung JH, Muratoglu OK (2009) Poly(vinyl alcohol)-acrylamide hydrogels as load-bearing cartilage substitute. Biomaterials 30:589-596.

[30] Wang H, Wang Z, Zhu B (2007) Preparation and properties of new non-loading and superhigh ammonium nitrate loading hydrogels. React Funct Polym 67:225-232.

[31] Zhang L, Rakotondradany F, Myles AJ, Fenniri H, Webster TJ (2009) Arginine-glycine-aspartic acid modified rosette nanotube-hydrogel composites for bone tissue engineering. Biomaterials 30(7):13091320.

[32] Xue W, Huglin MB, Liao B, Jones TGJ (2007) Swelling behaviour of crosslinked hydrogels based on (2-hydroxyethyl methacrylate) with a zwitterionic comonomer (1-3-sulfopropyl-2-vinyl-pyridinium-betaine). Eur Polym J 43:915-927.

[33] Reddy TT, Lavenant L, Lefebvre J, Renard D (2006) Swelling behavior and controlled release of theophylline and sulfamethoxazole drugs in $\beta$-Lactoglobulin protein gels obtained by phase separation in water/ethanol mixture. Biomacromolecules 7:323-330.

[34] Sriamornsak P, Thirawong N, Weerapol Y, Nunthanid J, Sungthongjeen S (2007) Swelling and erosion of pectin matrix tablets and their impact on drug release behavior. Eur J Pharm Sci 67:211-219. 
[35] Ritger PL, Peppas N (1987) A simple equation for description of solute release I. Fickian and nonFickian release from non-sweliable devices in the form of slabs, spheres, cylinders or discs. J Control Rel 5:23-36.

[36] Bortoletto-Santos R, Ribeiro C, Polito WL (2016) Controlled release of nitrogen-source fertilizers by natural-oil-based poly(urethane) coatings: the kinetic aspects of urea release. J Appl Polym Sci 133:43790.

[37] Kloprogge JT, Frost RL (1999) Fourier transform infrared and raman spectroscopic study of the local structure of Mg-, Ni-, and co-hydrotalcites. J Sol Stat Chem 146:506-515.

[38] Whilton NT, Vickers PJ, Mann SJ (1997) Bioinorganic clays: synthesis and characterization of aminoand polyamino acid intercalated layered double hydroxides. J Mater Chem 7:1623-1629.

[39] Otero V, Sanches D, Montagner C, Vilarigues M, Carlyle L, Lopes J, Melo M (2014) Characterisation of metal carboxylates by Raman and infrared spectroscopy in works of art. J Raman Spectrosc 45:11971206.

[40] Caulfield MJ, Qiao GG, Solomon DH (2002) Some aspects of the properties and degradation of polyacrylamides. Chem Rev 102:3067-3083.

[41] Liang HF, Hong MH, Ho RM, Chung CK, Lin YH, Chen $\mathrm{CH}$, Sung HW (2004) Novel method using a temperature-sensitive polymer (methylcellulose) to thermally gel aqueous alginate as a pH-sensitive hydrogel. Macromolecules 5:1917-1925.

[42] Bortolin A, Aouada FA, Moura MR, Ribeiro C, Longo E, Mattoso LHC (2012) Application of polysaccharide hydrogels in adsorption and controlled-extended release of fertilizers processes. J Appl Polym Sci 123:2291-2298.

[43] Aouada FA, Bortolin A, Moura MR, Longo E, Mattoso LHC (2012) Synthesis and characterization of novel pH sensitive PAAM-PMAA-CMC hydrogels and their applications in the controlled release of fertilizer. Hydrogels: Synthesis, Characterization and Applications. Nova Science Publishers, Inc. pp. 279298.

[44] Yang H, Liu J, Zhou Q, Ji H (2019) The re-swelling behavior of superabsorbent polymers (SAPs) in hardened cement paste with an artificial crack. Mater Struct 52:103.

\section{Figures}




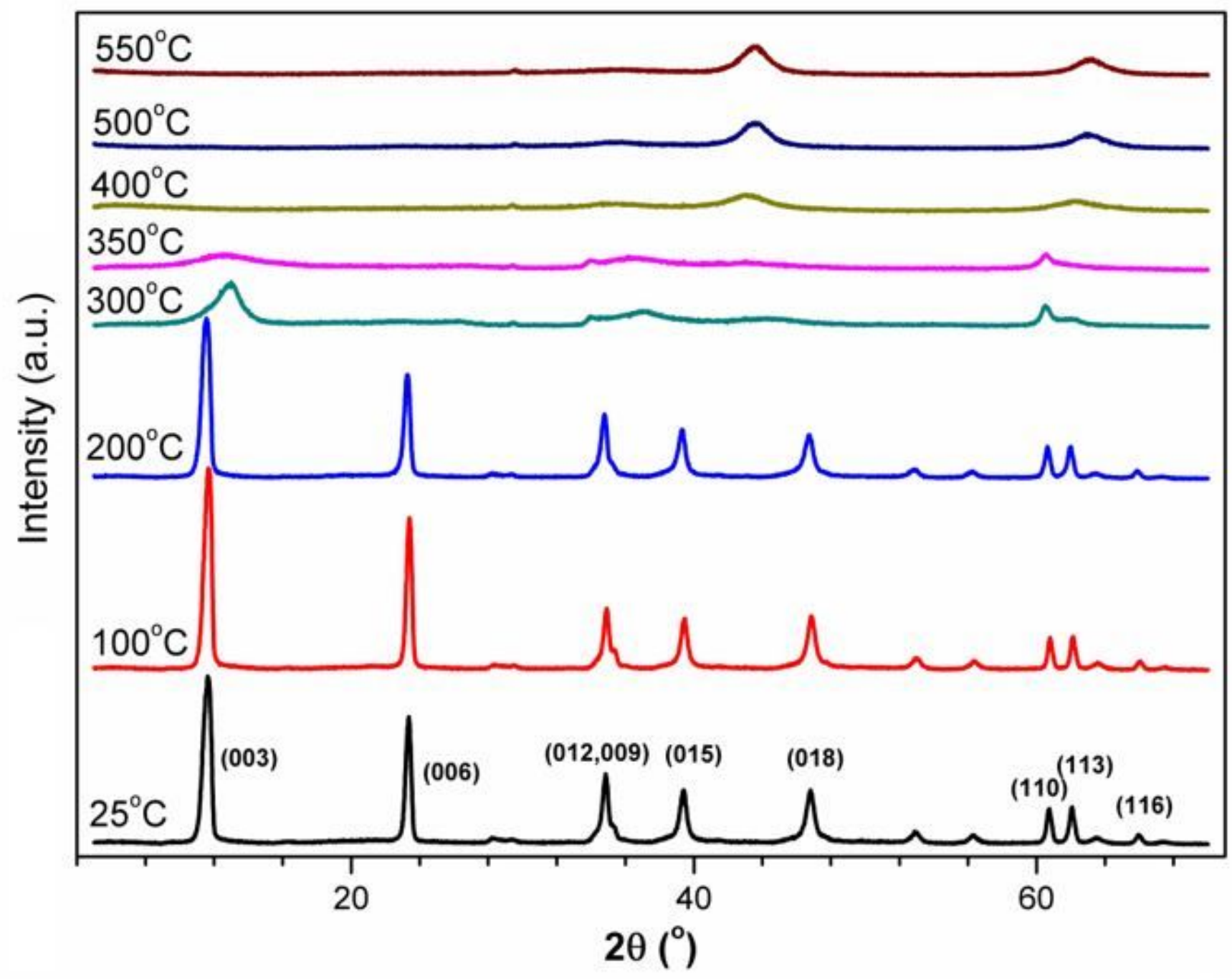

Figure 1

X-ray Diffraction (XRD) patterns of hydrotalcite treated at different temperatures. 

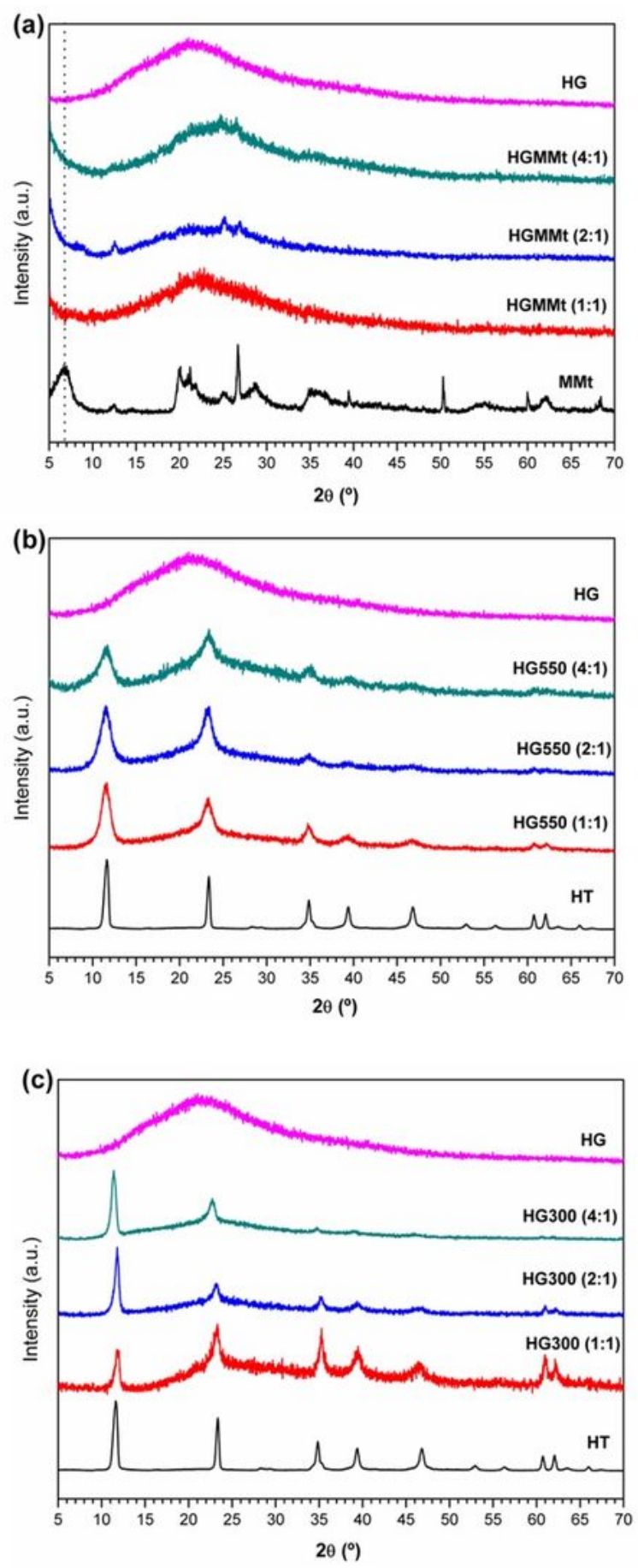

\section{Figure 2}

X-ray Diffraction (XRD) patterns of hydrogels synthesized with different proportions (by mass) of montmorillonite (a) and hydrotalcite calcined at (b) $550{ }^{\circ} \mathrm{C}$ and (c) $300{ }^{\circ} \mathrm{C}$. 

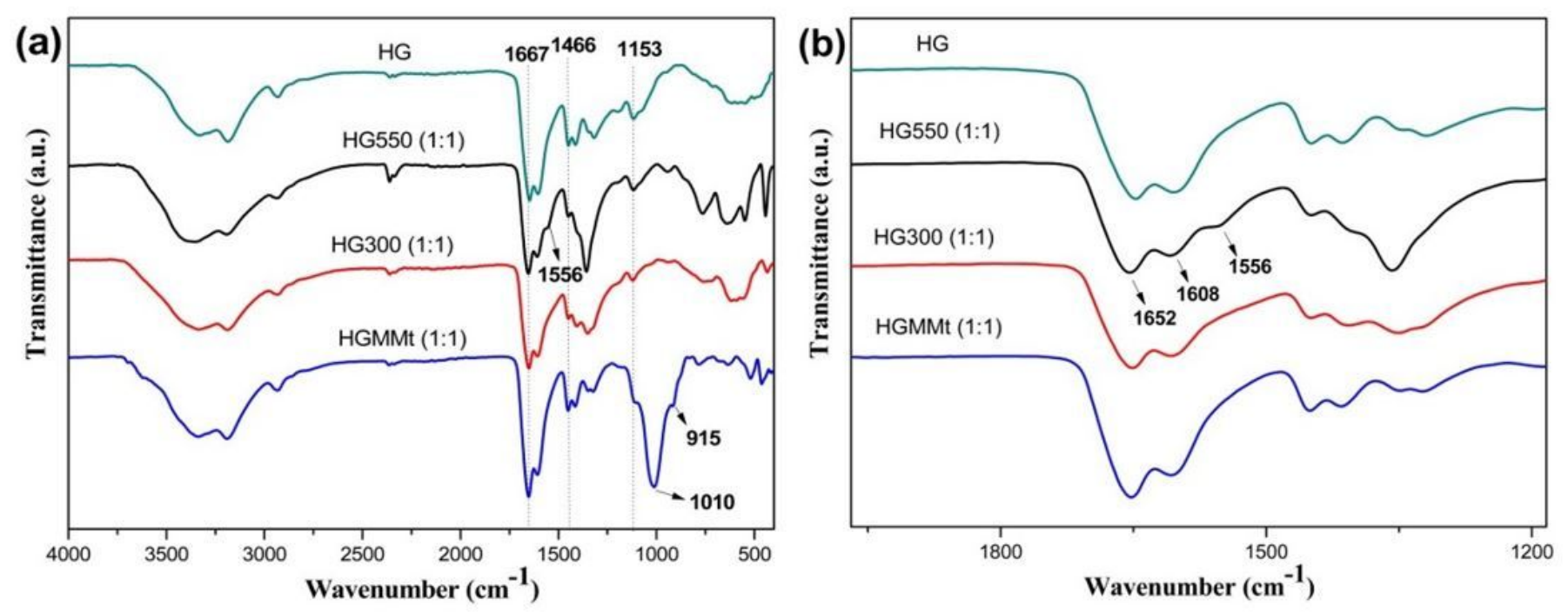

Figure 3

(a) FTIR spectra and (b) detailed view in the region between 1800 and $1500 \mathrm{~cm}-1$ of pure hydrogel (HG) and its respective nanocomposites with calcined hydrotalcite $\left(550\right.$ and $\left.300^{\circ} \mathrm{C}\right)$ and $\mathrm{MMt}$. 


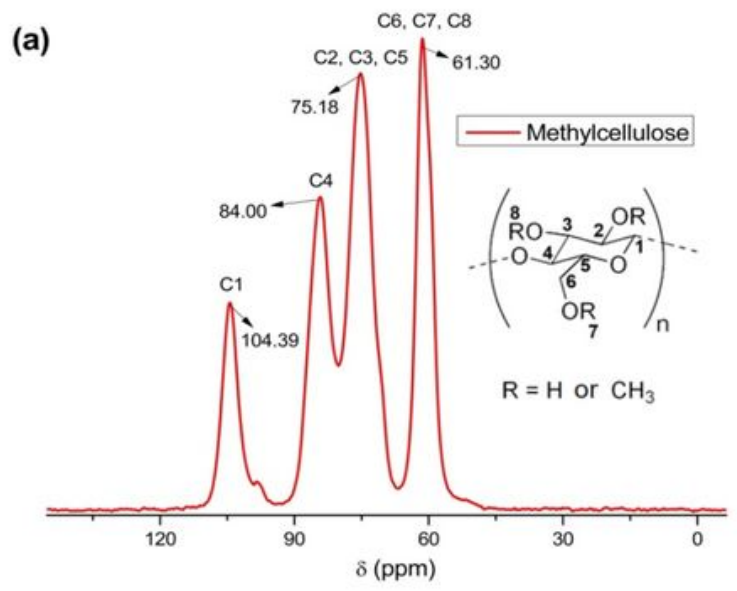

(b)
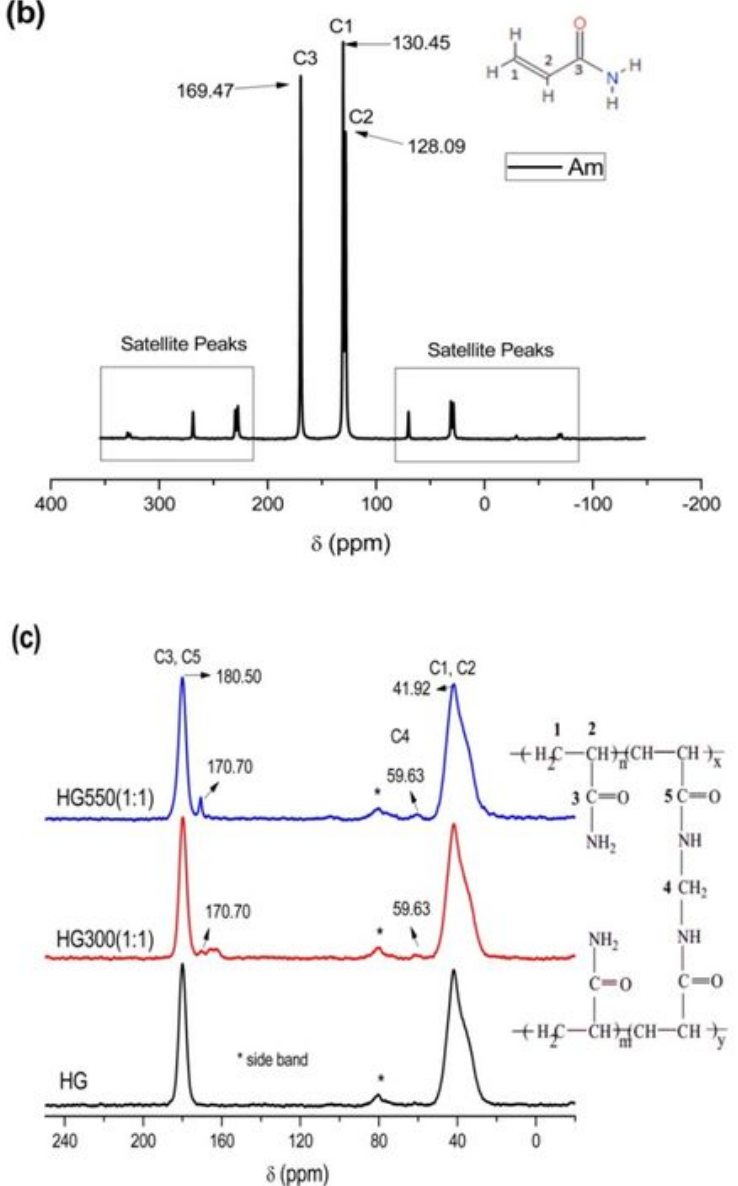

\section{Figure 4}

High-resolution solid-state 13C-NMR spectra of (a) methylcellulose (MC), (b) acrylamide (Am) and (c) synthesized NC hydrogels. The structures of MC, Am and PAAm are included as inserts. 

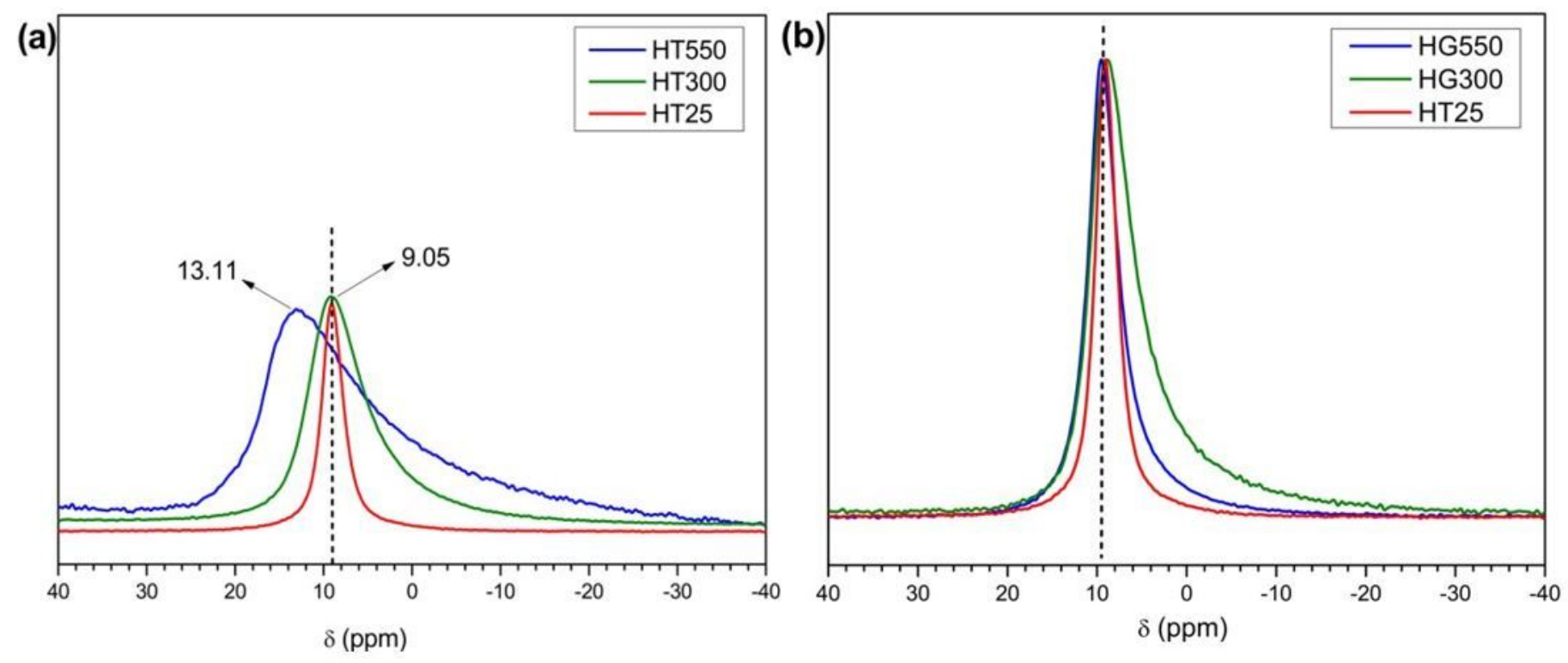

\section{Figure 5}

27Al-NMR spectra of (a) hydrotalcite and (b) modified hydrogels with hydrotalcite. 

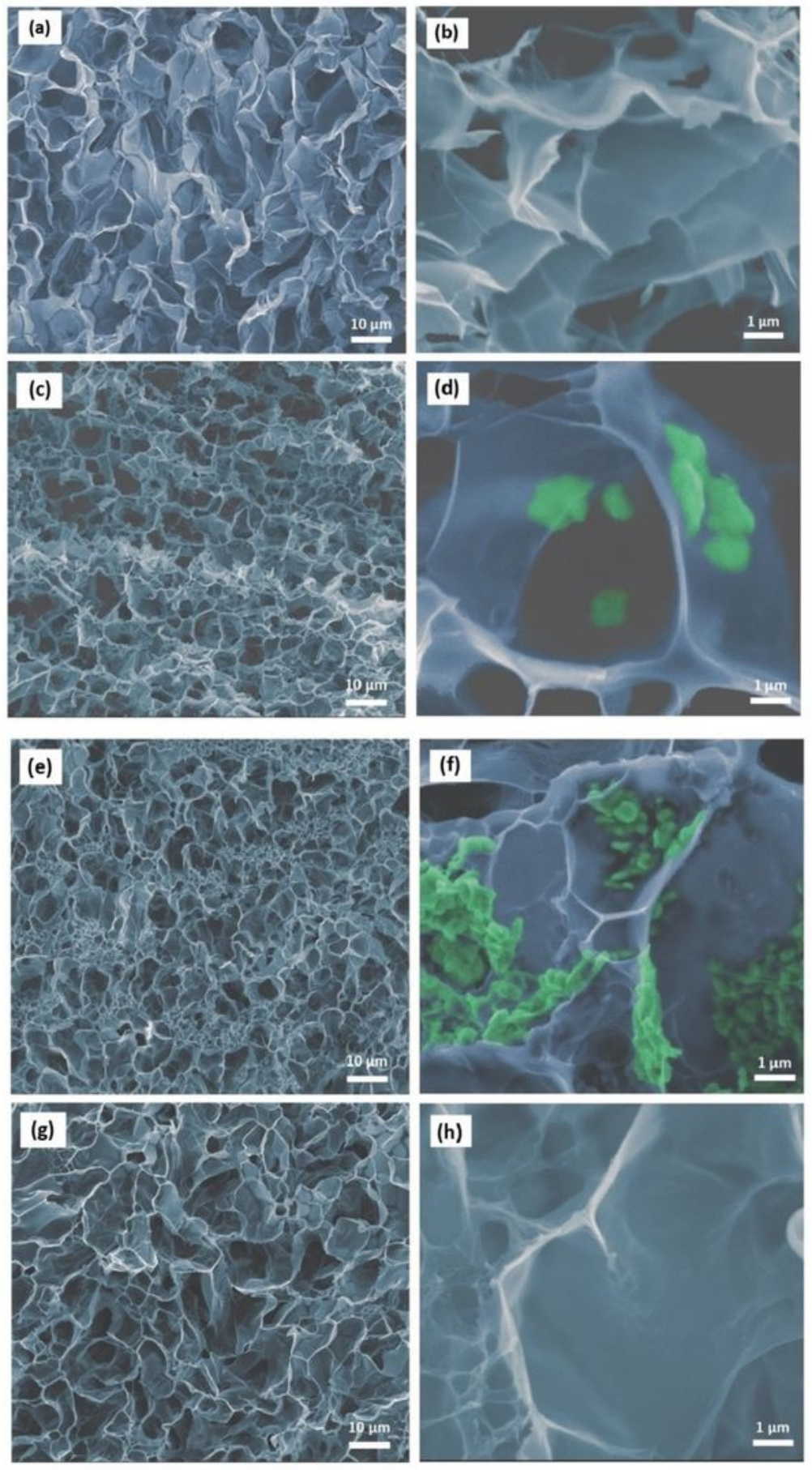

\section{Figure 6}

Scanning Electron Microscopy (SEM) images with two different magnifications of: (a-b) HG (1:0), (c-d) HG550 (1:1), (e-f) HG300 (1:1) and (g-h) HGMMt (1:1). The hydrogel and lamellar material are highlighted in blue and green, respectively. Original images are available in the Supplementary Material - Figure S1. 

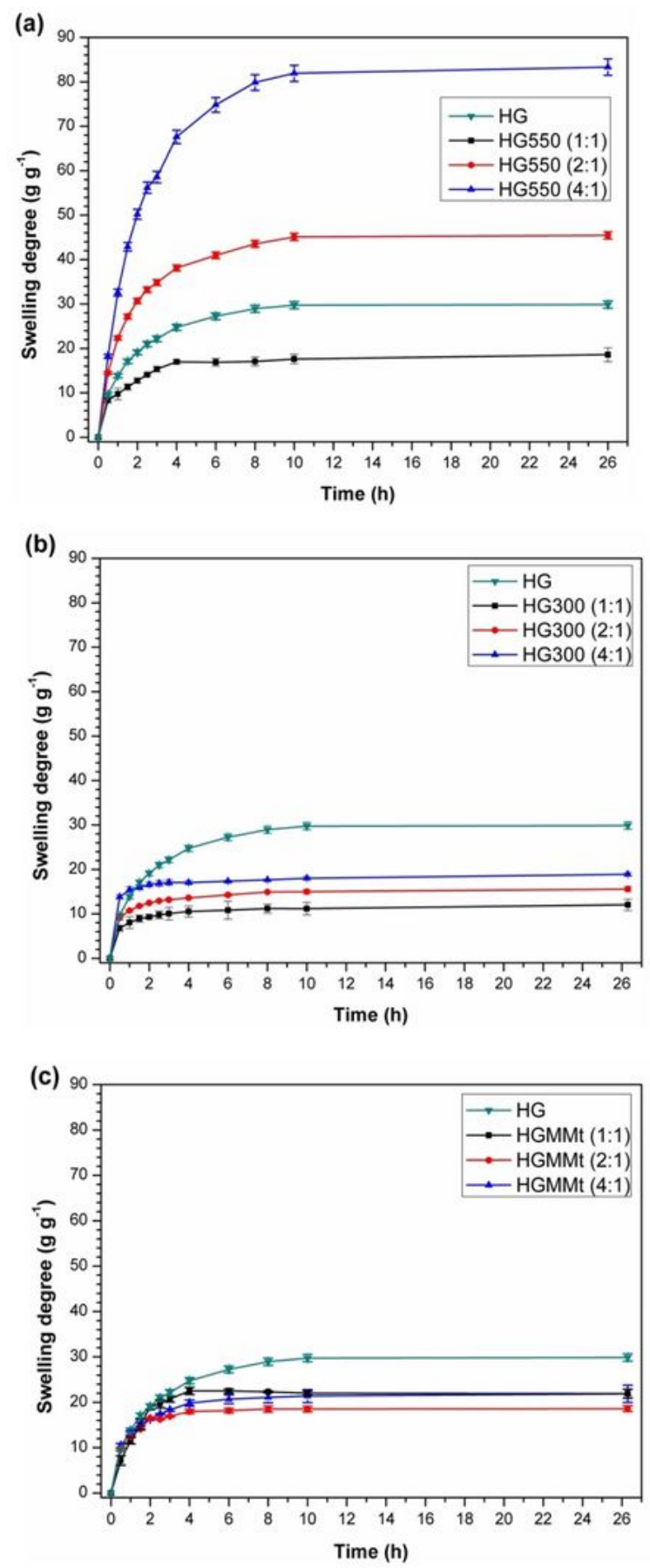

Figure 7

Swelling degree as a function of time for synthesized hydrogels with different contents and types of lamellar materials: (a) HG550, (b) HG300 and (c) HGMMt. 


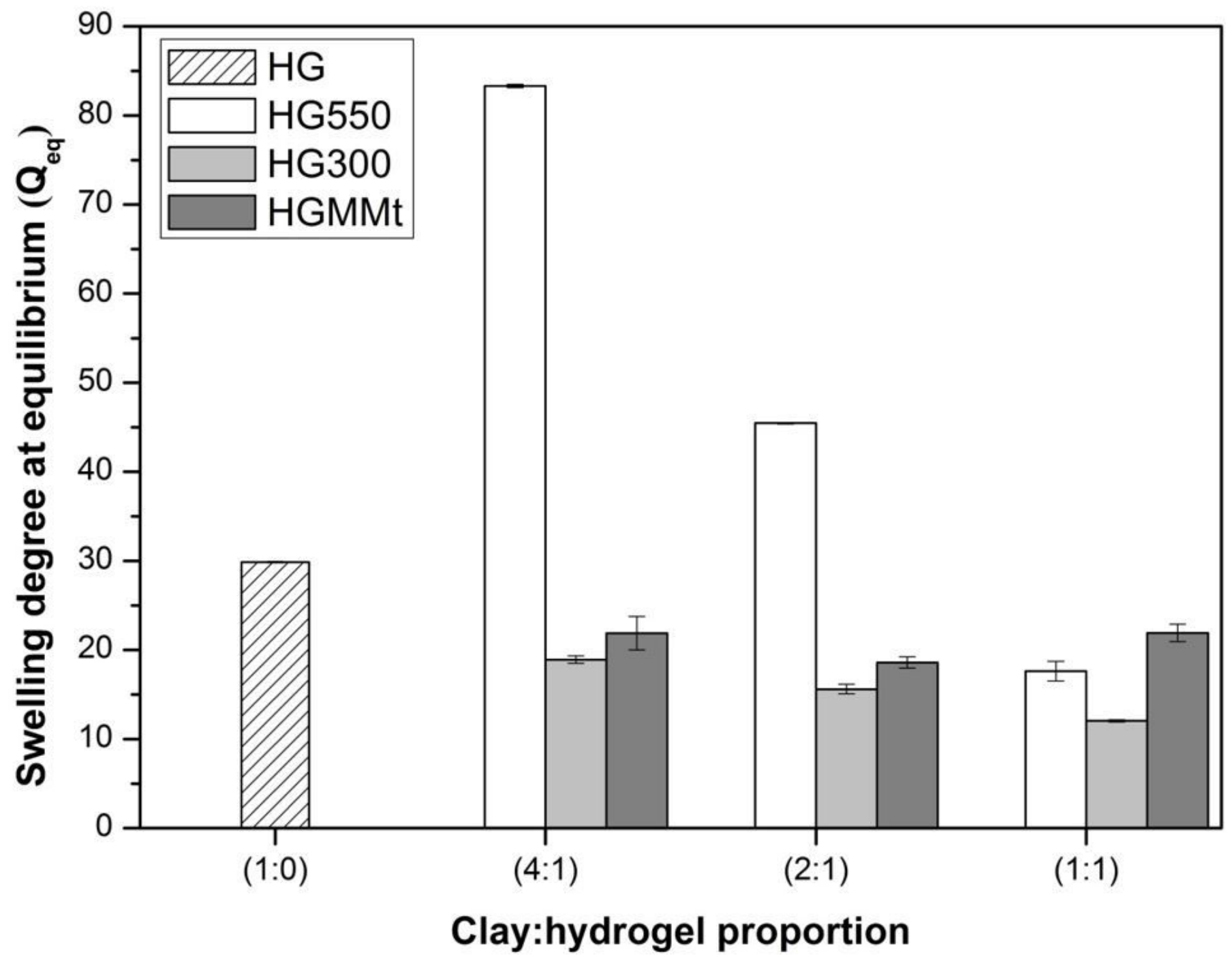

Figure 8

Comparison of swelling degree at equilibrium (Qeq) for different hydrogels synthesized using water as a swelling medium. 

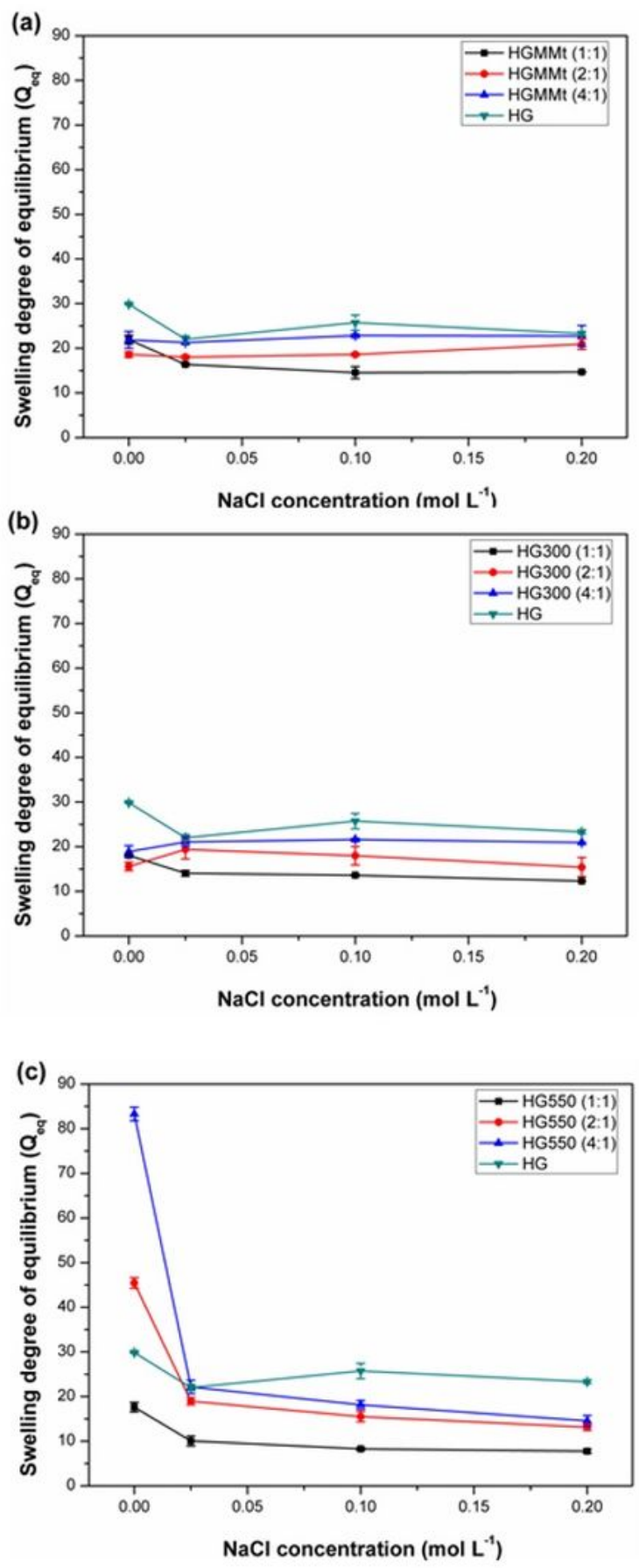

Figure 9

Swelling degree at equilibrium (Qeq) at different concentrations of $\mathrm{NaCl}$ for $\mathrm{HG}$ compared to (a) HGMMt, (b) HG30O and (c) HG550. 

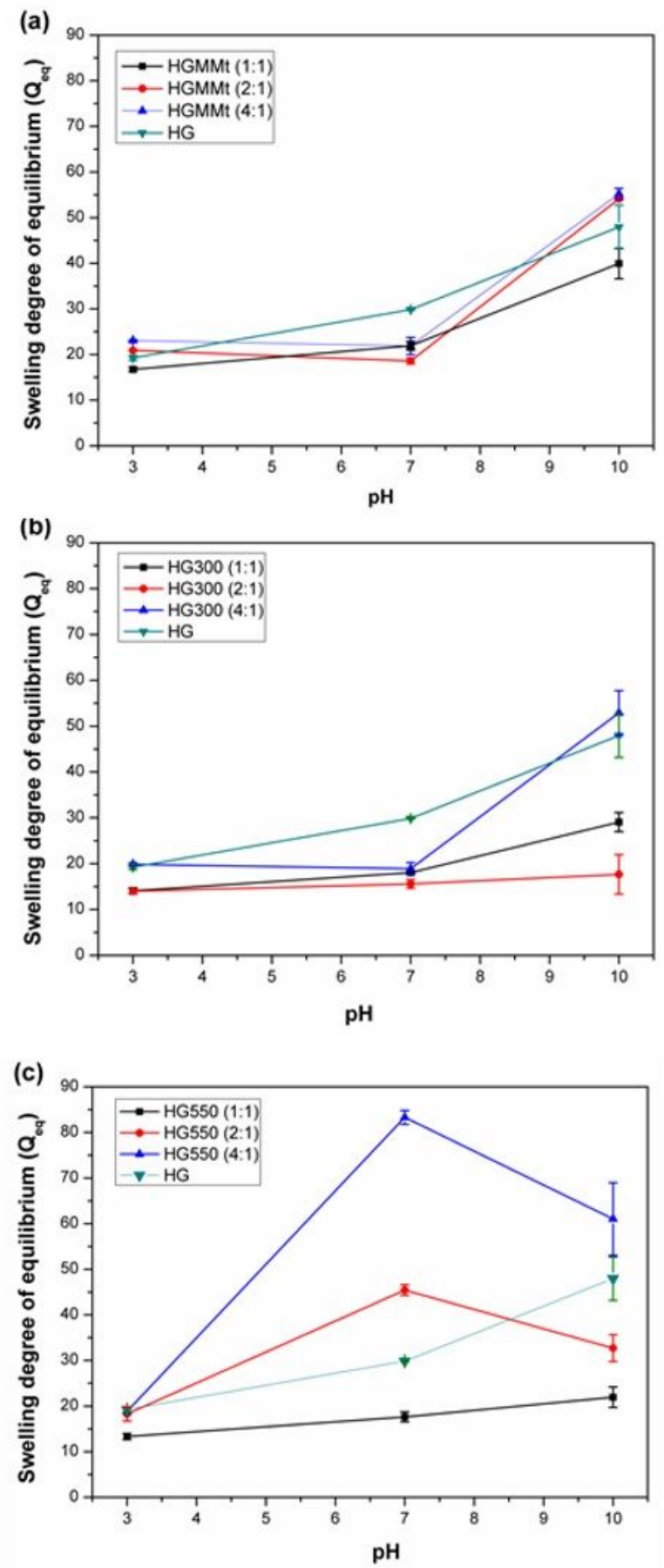

Figure 10

Swelling degree of equilibrium (Qeq) at different $\mathrm{pH}$ values for $\mathrm{HG}$ compared to (a) HGMMt, (b) HG300 and (c) HG550. 

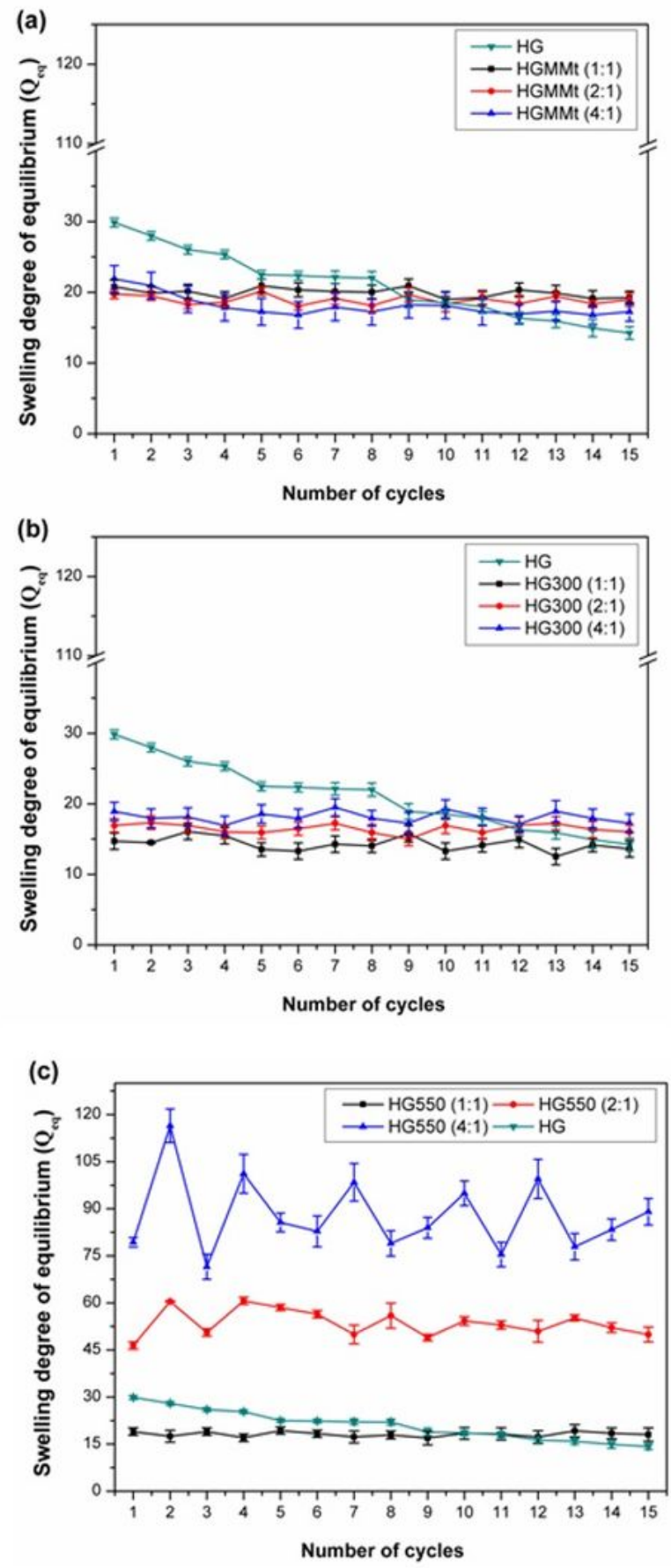

\section{Figure 11}

Comparison of swelling degree at equilibrium (Qeq) evolution with swelling/drying cycle number for (a) HGMMt, (b) HG300 and (c) HG550.

\section{Supplementary Files}


This is a list of supplementary files associated with this preprint. Click to download.

- SupplementaryMaterial.docx 